\title{
Characterization of $\gamma$-Aminobutyric acid(GABA) produced by a lactic acid bacterium from button mushroom bed
}

\author{
Yun-Seok Lee ${ }^{1}$, Tae-Young Song ${ }^{1}$, Won-Sik Kong ${ }^{2}$ and Min-Ho Yoon ${ }^{1 *}$ \\ ${ }^{1}$ Department of Bio-Environmental Chemistry, Chungnam National University, 99 Daehak-Ro, Yusung-Gu, \\ Daejeon 305-764, Republic of Korea \\ ${ }^{2}$ Mushroom Research Division, National Institute of Horticultural \& Herbal Science, RDA, Eumseong, Chungbuk, 369-873, Korea.
}

(Received November 18, 2013 / Revised December 27, 2013 / Accepted December 30, 2013)

\begin{abstract}
Aminobutyric acid(GABA) is a four carbon non-protein amino acid that has several well-known physiological functions, such as a postsynaptic inhibitory neurotransmitter in the brain and induction of hypotensive and tranquilizer effects. A lactic acid bacterium was isolated from button mushroom bed, which is showing high GABA productivity by TLC or HPLC analysis. The strain was identified as Lactobacillus hilgardii by analysis of 16S rDNA gene sequence. When the maximum production of GABA by L. hilgardii was investigated with various concentration of monosodium glutamate, the yield of GABA reached to be $53.65 \mathrm{mM}$ at $1 \%$ mono sodium glutamate (MSG) in flask cultivation. A Glutamate decarboxylase (GAD) enzyme, which was known to convert MSG to GABA, was purified from a cell-free extract of $L$. hilgardii and the molecular weights of purified GAD was estimated to 60,000 by SDS-PAGE. The optimum $\mathrm{pH}$ and temperature of GAD were at $\mathrm{pH} 4.6$ and at $37^{\circ} \mathrm{C}$, respectively. The GAD activity was increased by the addition of sulfate ions such as ammonium sulfate, sodium sulfate and magnesium sulfate, indicating that the increase of hydrophobic interaction causes the increase of GAD activity.
\end{abstract}

Keywords $-\gamma$-Aminobutyric acid(GABA), Glutamate decarboxylase(GAD), Lactobacillus hilgardii, Purification

\section{Introduction}

Gamma-aminobutyric acid (GABA) is known as a nonprotein amino acid produced by the $\alpha$ decarboxylation of L-glutamic acid in a reaction catalyzed by glutamate decarboxylase (EC 4.1.1.15) (Jakoby and Scoott, 1959).

GABA has several well-known physiological functions, such as neurotransmission, induction of hypotensive, diuretic effects, and tranquilizer effects (Jakobs et al., 1993; Guin Ting Wong et al., 2003). It is known that GABA is involved in the regulation of neurological disorder like seizures, Parkinson's disease, huntington's disease and Alzheimer's disease (Stanton, 1963). In addition, GABA induces insulin secretion strongly from the pancreas (Adeghate and Ponery, 2002) and prevents diabetic conditions (Hagiwara et al., 2004). Due to the physiological functions of GABA, development of functional foods containing GABA at high concentration has been actively pursued (Tsushida and Murai, 1987; Saikusa et al., 1994). GABA enrichment has been achieved in anaerobic-incubated tea (gabaron tea) (Tsushida and Murai, 1987) and in rice germ soaked in water (Saikusa et al., 1994), and in tea leaves (Lin et al., 2012). GABA production by various micro-organisms has been reported, including bacteria (Smith et al., 1992; Maras et al., 1992), fungi (Kono and Himeno, 2000), and yeasts (Hao and Schmit, 1993).

Glutamate decarboxylase (GAD) [EC: 4.1.1.15] is considered responsible for GABA production by GABA-producing strains of lactic acid bacteria(LAB) such as Lactobacillus and Lactococcus. GAD has been isolated from a wide variety of sources, and its biochemical properties have been characterized (Nomura et al., 1999, 2000). Ueno et al. (1997) puried GAD from Lactobacillus brevis and then determined its biochemical characterization. Nomura et al. (1998) characterized GAD and cloned the gene responsible for GAD activity in Lactobacillus lactis, and found that $L$. lactis contained only one GAD gene. Although GAD is widely distributed in LAB,

*Corresponding author: mhyoon@cnu.ac.kr 
GABA-producing ability varies widely among LAB.

In the present study, a GABA producing bacterium, Lactobacillus hilgardii was isolated and the cultivation conditions suitable for GABA production and the properties of GAD purified from the strain were assessed under laboratory conditions.

\section{Materials and Methods}

Screening of GABA-producing LAB. The Gammaaminobutyric acid (GABA) producing bacteria were isolated from button mushroom bed in Buyeo-Gun, Chungchugnam-do province. Serially diluted aliquots of button mushroom bed samples were inoculated in Lactobacilli MRS(Difco, Detroit, USA) broth containing $1 \%$ mono sodium glutamate (MSG) and grown for $72 \mathrm{~h}$ at $36^{\circ} \mathrm{C}$. GABA content in the culture supernatants after incubation was estimated by TLC to select GABA producing bacteria and finally measured by HPLC analysis.

Cultivation. The preculture of selected GABA producing bacteria was grown stationary at $36^{\circ} \mathrm{C}$ for $48 \mathrm{~h}$ in Lacto bacilli MRS broth. The culture was inoculated into the GYP medium as follows: $1 \%$ glucose, $1 \%$ yeast extract, $0.5 \%$ polypeptone, $0.2 \%$ sodium acetate, $20 \mathrm{ppm} \mathrm{MgSO}_{4} \cdot 7 \mathrm{H}_{2} \mathrm{O}, 1 \mathrm{ppm} \mathrm{MnSO}_{4} \cdot$ $7 \mathrm{H}_{2} \mathrm{O}, 1 \mathrm{ppm} \quad \mathrm{FeSO}_{4} \cdot 7 \mathrm{H}_{2} \mathrm{O}, 1 \mathrm{ppm} \mathrm{NaCl}, \mathrm{pH} 6.8$ containing $1 \% \mathrm{MSG}$ and cultivated at $30^{\circ} \mathrm{C}$ for $72 \mathrm{~h}$ in Erlenmeyer flask(1 liter) containing $400 \mathrm{ml}$ of culture medium without aeration or agitation. The culture broth at given cultivation times was withdrawn every $12 \mathrm{~h}$ from the fermentation medium and filtered with $0.45 \mu \mathrm{m}$ of cellulose acetate filter for HPLC analysis.

Assay of GABA. The Levels of GABA were qualitatively determined by TLC. Culture broth was centrifuged at $8,000 \times \mathrm{g}$ for $30 \mathrm{~min}$. TLC analysis was conducted using an n-butanol : acetic acid : distilled water( $3: 2: 1, \mathrm{v} / \mathrm{v} / \mathrm{v})$ of solvent mixture as a mobile phase, and the plates using Kiesel gel F254 (Merck) were subsequently immerged into $0.2 \%$ ninhydrin solution and then heating at $95^{\circ} \mathrm{C}$ for color developing. The amount of GABA produced by GABA producing bacteria was also determined using HPLC system (Agilent series 1100, USA). The used column was a ZORBOX Eclipse XDB $\mathrm{C}_{18}(4.6 \mathrm{~mm} \times 150 \mathrm{~mm}, 5 \mu \mathrm{m}$, Agilent Technologies), a UV detector $(338 \mathrm{~nm})$ at $40^{\circ} \mathrm{C}$ with UV detector $(338 \mathrm{~nm})$. The mobile phase was comprised of (A) $40 \mathrm{mM} \mathrm{Na} 2 \mathrm{HPO}_{4}, \mathrm{pH} 7.8$ and (B) ACN:MeOH:water $(45: 45: 10, \mathrm{v} / \mathrm{v} / \mathrm{v})$ at flow rate of $0.2 \mathrm{ml} / \mathrm{min}$. The sample were filtered with $0.45 \mu \mathrm{m}$ of cellulose acetate filter and $10 \mu \mathrm{l}$ of the filtrate was injected. HPLC profiles of the culture filtrate was analyzed by comparison with the elution profile of those of authentic standard injected separately.

Identification of the selected strain. The partial sequencing of 16S rRNA for the bacterial strains was done with the help of DNA sequencing service, SOLGENT, Daejeon, South Korea using universal primers, 27F (5'-AGAGTTTGATCCTGGCTCAG-3') and 1492R (5'-GGTTACCTTGTTACGACTT-3'). The online program BLAST was used in identifying the related sequences with known taxonomic information available at the databank of NCBI (http:// www.ncbi.nlm.nih.gov/BLAST). A phylogenetic tree was constructed using CLUSTAL $\mathrm{X}$ program (Thompson et al., 1997), which involved sequence alignment by neighbor joining method (Saitou and Nei, 1987) and maximum parsimony using the MEGA4 program (Kumar et al., 2001). Grouping of sequences was based on confidence values obtained by bootstrap analysis of 1,000 replicates. Gaps were edited in the BioEdit program and evolutionary distances were calculated using Kimura two parameter model. Reference sequences were retrieved from GenBank under the accession numbers indicated in the trees.

Enzyme assay. To measure the activity of glutamate decarboxylase $(\mathrm{GAD})$, enzyme solution $(0.1 \mathrm{ml})$ purified from the culture filtrate was mixed with $0.1 \mathrm{ml}$ of $4 \mathrm{M}$ ammonium sulfate and $1.3 \mathrm{ml}$ of the substrate solution containing $0.4 \mathrm{M} \mathrm{NaCl}, 0.2 \mathrm{mM}$ pyridoxal 5'-phosphate and $20 \mathrm{mM}$ sodium glutamate in $0.2 \mathrm{M}$ pyridine $-\mathrm{HCl}$ buffer $(\mathrm{pH} 4.6)$ and the mixture was incubated at $37^{\circ} \mathrm{C}$ for $60 \mathrm{~min}$. After the incubation, the reaction was stopped in boiling water for $5 \mathrm{~min}$ and the activity of 
GAD was analyzed by TLC or HPLC analysis.

Purification of glutamate decarboxylase. The organism was grown as described earlier and the cells were separated by centrifugation at $10,000 \mathrm{rpm}, 4^{\circ} \mathrm{C}$ for $15 \mathrm{~min}$ after $24 \mathrm{~h}$ of incubation. The supernatant was used for the crude GAD preparation. The enzyme was precipitated from the supernatant by the gradual addition of solid ammonium sulfate with gentle stirring to 60 and $70 \%$ saturation and precipitate was collected by centrifugation at $12,000 \mathrm{rpm}$ for $30 \mathrm{~min}$. Then the precipitate was dissolved in $20 \mathrm{Mm}$ sodium phosphate buffer, $\mathrm{pH} 7.0$ and dialyzed overnight at $4^{\circ} \mathrm{C}$ against the same buffer. The DAD activity and protein concentration was measured and specific activity was calculated.

Gel Filtration Chromatography. The dialyzed ammonium sulfate fractions were concentrated using an ultrafiltration (Amicon® Ultra-0.5) centrifugation filter devices. The resulting concentrated sample $(1-2 \mathrm{ml}, 1.0-$ $1.5 \mathrm{mg}$ ) was applied to a Sephacryl S-300 gel filtration column XK $(60 \times 12 \mathrm{~cm})$ equilibrated with $20 \mathrm{Mm}$ sodium phosphate buffer, pH 7.0 containing $0.1 \mathrm{mM}$ pyridoxal 5'-phosphate, $0.2 \mathrm{mM}$ pyridoxal 5'-phosphate, $0.1 \mathrm{mM}$ 2-mercaptoethanol, $0.15 \mathrm{M} \mathrm{NaCl}$ and $5 \mathrm{Mm}$ EDTA, and was eluted using at a flow rate of $1.0 \mathrm{ml} /$ min. The fractions (approximately $1.5 \mathrm{ml}$ of each) possessing GAD activity were pooled and concentrated. The protein content was determined using the method previously described (Lowry et al., 1951), with bovine serum albumin (BSA) as the standard.

Molecular weight determination by SDS-PAGE. The purified GAD was subjected to sodium dodecyl sulphate polyacrylamide gel electrophoresis (SDSPAGE) to estimate the molecular weight of the protein. SDS-PAGE was carried out with the use of $12 \%(\mathrm{w} / \mathrm{v})$ separating gel according to the method of Laemmli (1970). Relative molecular weight of the enzyme was estimated by comparison with protein molecular weight markers (PageRuler ${ }^{\mathrm{TM}}$ Prestained Protein Ladder. Fermentas). After electrophoresis, the gel was stained with Coomassie brilliant blue R-250 to locate protein bands.

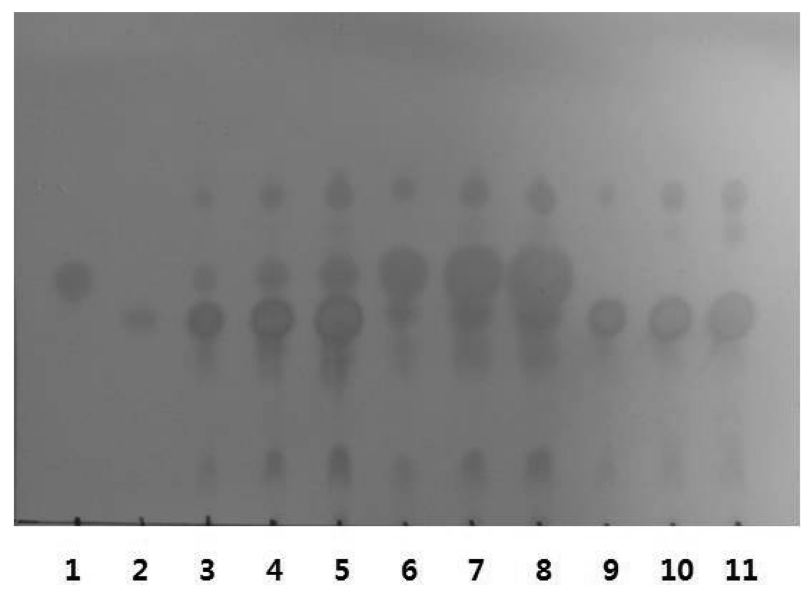

Fig. 1. Comparison of GABA production by the selected strains incubated with different MSGs on TLC Lane 1 : GABA standard $(0.1 \%)$

Lane 2 : MSG standard $(0.1 \%)$

Lane 3-5: Postive control (Lactobacillus brevis) incubated with $0.5,1.0,1.5 \%$ of MSG

Lane 6-8 : Lactobacillus hilgardii MYA-9 incubated with $0.5,1.0,1.5 \%$ of MSG

Lane 9-11 : Negative control strains

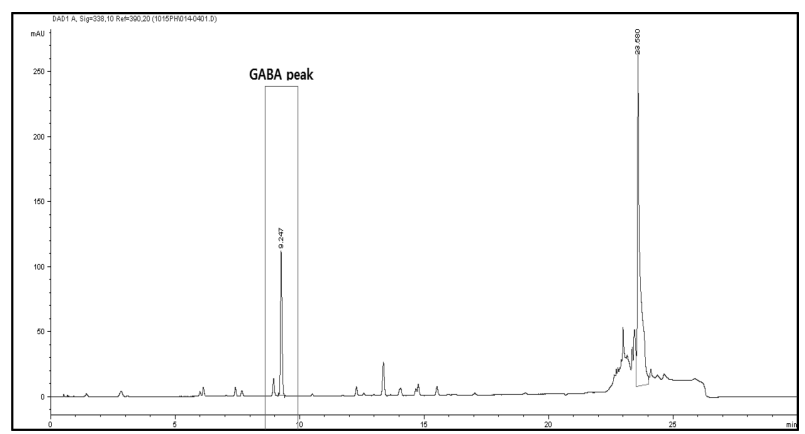

Fig. 2. HPLC analysis GABA produced by Lactobacillus hilgardii MYA-9.

\section{Results and Discussion}

Isolation of GABA-producing bacteria. To screen LAB strains that produce Gamma-aminobutyric acid (GABA) at high-level concentration from button mushroom bed in Buyeo-Gun, Chungchugnam-do province, South Korea, GABA producing bacteria in various concentration of MSG were selected by TLC analysis(Fig. 1). The selected strains were cultivated for $48 \mathrm{~h}$ at $36^{\circ} \mathrm{C}$ in $100 \mathrm{ml}$ MRS broth medium containing $1 \%$ of MSG through Erlenmeyer flask incubation. When the amount of GABA produced by the strains were measured by HPLC analysis, the isolate MYA-9 appeared to produce the 


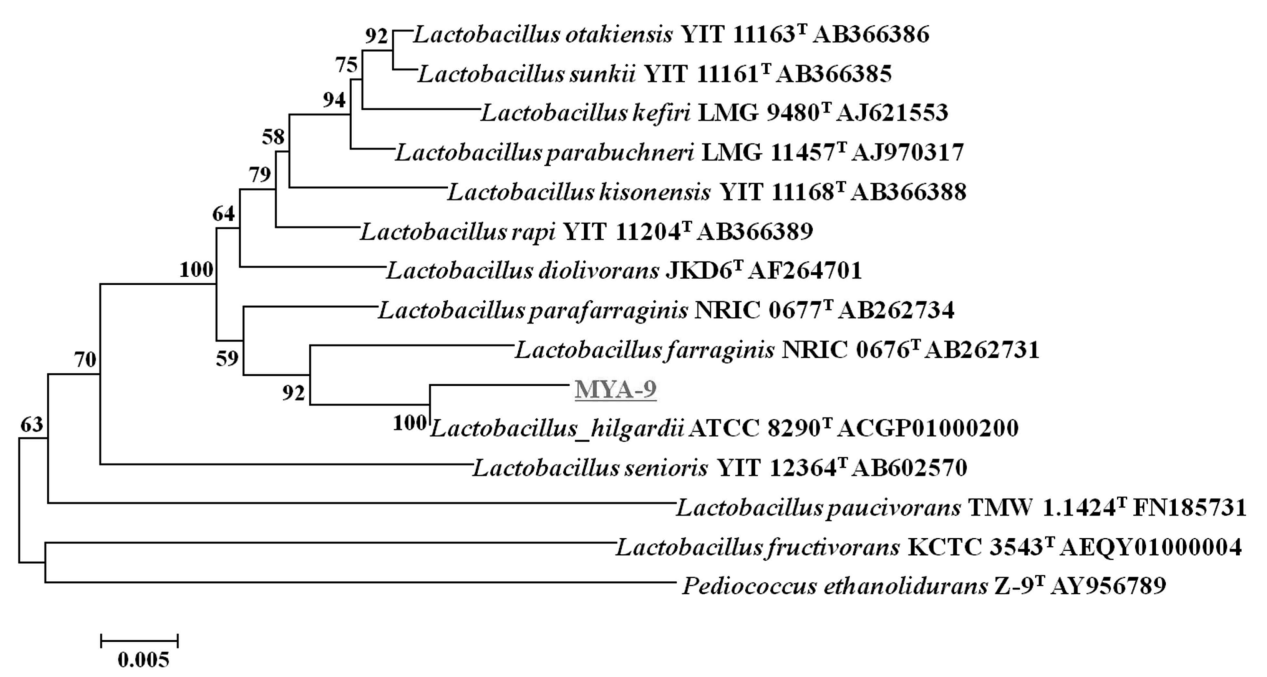

Fig. 3. Phylogetic tree showing the relationship of the strains MYA-9. The tree is based on 16s rDNA sequence data and constructed by using the neighbor-joining method.

highest amount of GABA among all selected strains as $53.65 \mathrm{mM}$ at $1 \% \mathrm{MSG}$ and the conversion rate of GABA from MSG reached to be about $97.46 \%$ (Fig. 2). The strain MYA-9 was finally selected for purifying the glutamate decarboxylase, based on the results of GABA producing ability.

Identification of strain MYA-9. According to the taxonomic identification using 16S rRNA sequence analysis, the strain MYA-9 showed close proximity as $99.085 \%$ homology with Lactobacillus hilgardii ATCC $8290^{\mathrm{T}}$. Phylogenetic tree (Fig. 3) shows the position of isolated bacterial strain with respect to the related Lactobacillus species.

Purification of GAD. Purification of the GAD from L. hilgardii MYA-9 was carried out by combination of ammonium sulfate precipitation (60\% and 70\%) and gel filtration chromatography procedures. The purified enzyme migrated as a single band in SDS-PAGE, indicating the homogeneity of the preparation and monomeric nature of the GAD. Apparent molecular mass of the GAD was about $60 \mathrm{kDa}$ (Fig. 4). The molecular mass of L. hilgardii MYA-9 GAD was comparable with most of the other bacterial strain GAD. Similar molecular masses have been reported by Hiraga et al, (2008) for Lactobacillus brevis (54 kDa) and Komatsuzaki et al. (2007) for Lactobacillus paracasei (57 kDa).

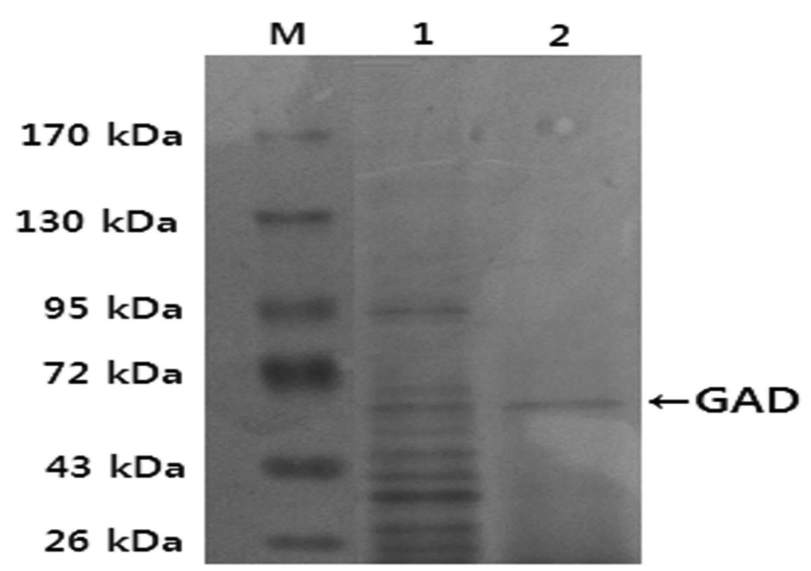

Fig. 4. SDS-PAGE of glutamate decarboxylase purified from Lactobacillus hilgardii MYA-9. Lane M: protein marker, Lane 1: culture filtrate, Lane 2: purified GAD

Effect of pH on GAD activity. The effect of $\mathrm{pH}$ on GAD activity are shown in Fig. 5 (a). The GAD activity appeared to be maintained over approximately $80 \%$ of the initial activity in the tested $\mathrm{pH}$ range from 3-7. The highest GAD activity (100\%) was found at $\mathrm{pH}$ 4.6. Furthermore, enzyme activity markedly decreased under alkaline $\mathrm{pH}$ conditions, showing $30-40 \%$ of its original activity at $\mathrm{pH} 7.5$ and 8.0. These results are in accordance with previous reports which showed optimum $\mathrm{pH}$ of 4.5 for several bacterial strains such as Lactobacillus brevis(Ueno et al, 1997), Lactobacillus paracasei (Noriko et al, 2005), Lactobacillus sakei (Yu, J.J. and Oh, S.H., 2011) that exhibited a maximum activity at range of $\mathrm{pH}$ 4-5. This suggested the 

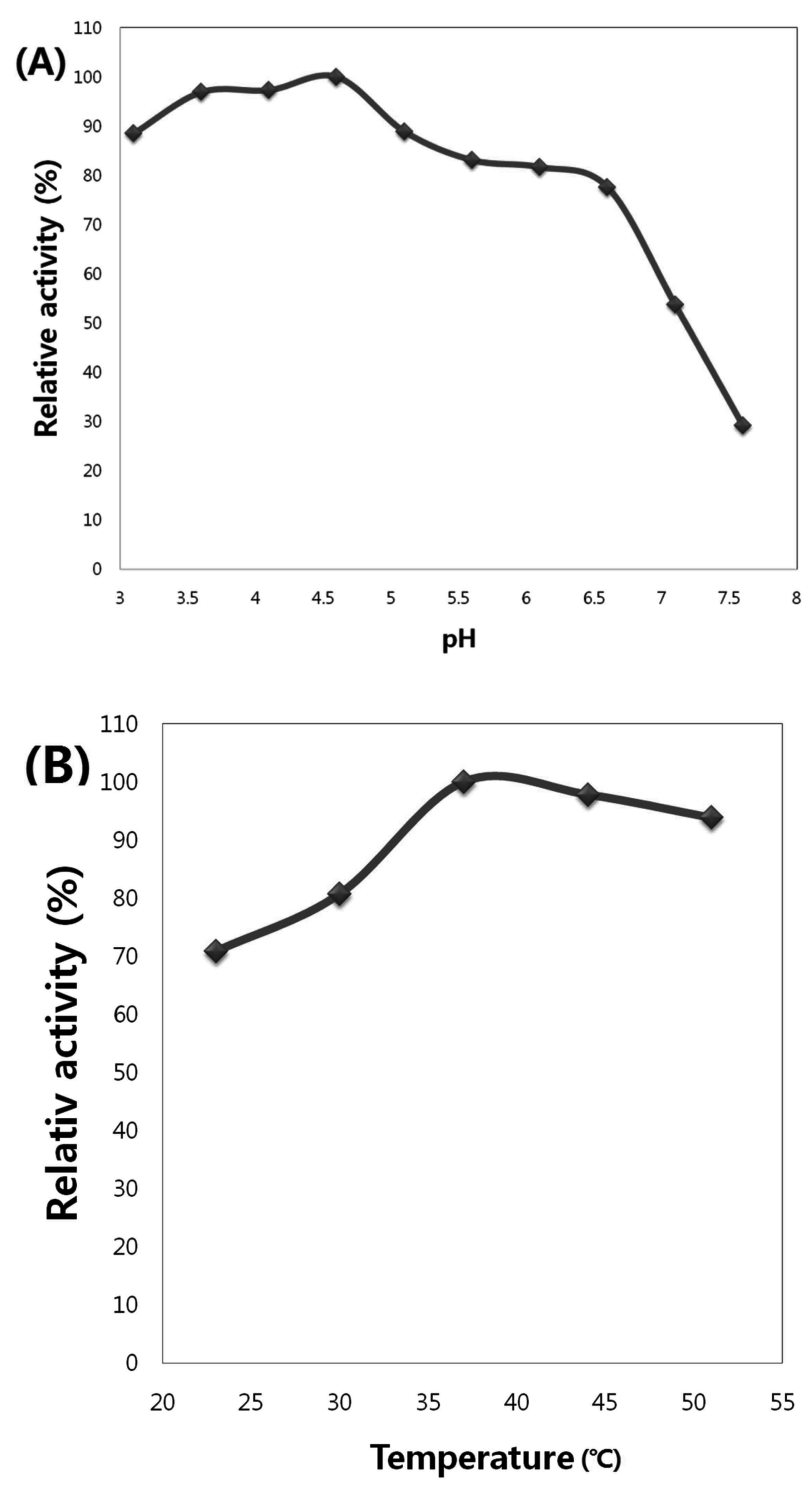

Fig. 5. Effects of $\mathrm{pH}$ and Temperature on GAD Activity from Lactobacillus hilgardii MYA-9. Optimum $\mathrm{pH}$ activity was measured in $0.2 \mathrm{M}$ pyridine- $\mathrm{HCl}$ buffer at various pHs. Optimum temperature activity was measured in $0.2 \mathrm{M}$ pyridine- $\mathrm{HCl}, \mathrm{pH} 4.6$ at various temperatures.

suitability of this GAD for GABA production may be highlighted by using in various industrial processes which carried out at acidic conditions.

Effect of temperature on GAD activity. Effect of temperature on GAD activity and stability are shown in Fig. 5 (b). The activity was active between $35^{\circ} \mathrm{C}$ and $45^{\circ} \mathrm{C}$ with an optimum at $37^{\circ} \mathrm{C}$. The activity was found to be increased rapidly above $37^{\circ} \mathrm{C}$, however decreased after $50^{\circ} \mathrm{C}$. The temperature stability showed that the enzyme lost its original

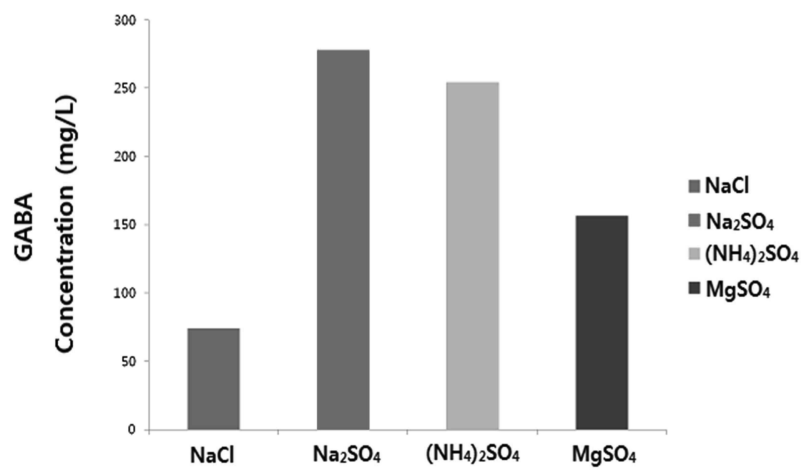

Fig. 6. Effects of different sulfate ions affecting on GAD Activity. The enzyme activity was estimated with measuring the amount of GABA produced in the presence of respective sulfates with $1 \mathrm{M}$ of concentration at $37^{\circ} \mathrm{C}, \mathrm{pH}$ 4.6.

stability approximately by $30 \%$ at room temperature $\left(30^{\circ} \mathrm{C}\right)$. There are many reports about temperature stability and activity of GAD. Yu et al., (2011) reported about GAD from Lactobacillus sakei with optimum activity at $30^{\circ} \mathrm{C}$ and $\mathrm{pH} 5.0$.

Effects of sulfate ions on GAD activity. When it was estimated that the effects of several sulfate ions on GAD activity, as shown in Fig. 6, the respective sulfate ions were found to increase GAD activity by around $150-270 \mathrm{mg} / \mathrm{L}$ at the concentration of $1 \mathrm{M}$. The effects on enzyme activity were enhanced by the order of sodium sulfate>ammonium sulfate> magnesium sulfate. This finding explained that the sulfate ions are essential to enhance GAD activity and the GABA producing bacteria obligatorily require the presence of sulfate ions in the medium to make GAD more active. Although the mechanism on activation of enzyme activity by a high concentration of ammonium sulfate(above $1 \mathrm{M}$ ) has not yet been clarified, the increased GAD activity in the presence of sulfate ions may be attributed to inducing either the conformational changes of enzyme by lowering $\mathrm{pH}$ of the reaction mixture or the increase of hydrophobic interaction under excess sulfate ion concentrations. Similar reports on the effects of sulfate ion for other bacterial GAD have also been observed by researchers (Hiraga et al, 2008), suggesting that GAD is essential to require the high concentration of sulfate ions for the 
conversion of GABA from MSG.

It is concluded that a GABA producing bacterium, Lactobacillus hilgardii MYA-9 was isolated from button mushroom bed and the strain has been found to be able to secrete GABA and GAD under the condition containing the high concentration of sulfate ions and 1\% MSG as substrate. The molecular mass, $60 \mathrm{kDa}$, of GAD purified from $L$. hilgardii MYA-9 was comparable with most of the other Lactobacillus strain GADs with 40-57 kDa. The highest GAD activity was found at an optimum $\mathrm{pH} 4.6$ and $37^{\circ} \mathrm{C}$, respectively. The increased GAD activity in the presence of sulfate ions may be attributed to inducing either the conformational changes of enzyme by lowering $\mathrm{pH}$ of the reaction mixture or the increase of hydrophobic interaction. Therefore, the sulfate ions are essential to enhance GAD activity and the GABA producing bacteria obligatorily require the presence of sulfate ions in the medium to make GAD more active.

\section{Acknowledgements}

This study was supported by a grant from the research project(No. PJ0067492011) of National Institute of Horticultural \& Herbal Science, Rural Development Administration, Republic of Korea.

\section{References}

Adeghate, E. and Ponery, A.S. 2002. GABA in the endocrine pancreas: Cellular localization and function in normal and diabetic rats. Tissue Cell. 34 : 1-6.

Hao, R. and Schmit, J.C. 1993. Cloning of the gene for glutamate decarboxylase and its expression during condition in Neurospora crassa. Biochem J. 293 : 735-738.

Hiraga, K., Ueno, Y. and Oda, K. 2008. Glutamate decarboxylase from Lactobacillus brevis: Activation by ammonium sulfate. Biosci. Biotechnol. Biochem. 72 : 1299-1306.

Jacobs, C., Jaeken, J. and Gibson, K.M. 1993. Inherited disorders of GABA metabolism. J Inherit Metab Dis. 16 : 704-715.

Jakoby, W.B. and Scott, E.M. 1959. aldehyde oxidation III. Succinic semialdehyde dehydrogenase. J Biol Chem. 234 : 937-40.

Kono, I. and Himeno, K. 2000. Changes in $\gamma$-Aminobutyric acid content during beni-koji making. Biosci Biotechnol Biochem. 64: 617-619.

Kumar, S., K., Tamura, I. Jakobsen, B., and Nei, M. 2001. MEGA2: molecular evolutionary genetics analysis software. Bioinformatics. 17:1244-1245.
Komatsuzaki, N., Nakamura, T., Kimura, T., SHIMA, T. 2008. Characterization of Glutamate Decarboxylase from a High ãAminobutyric Acid (GABA)-Producer, Lactobacillus paracasei . Biosci. Biotechnol. Biochem. 72 : 278-285.

Laemmli, U.K. 1970. Cleavage of structural proteins during the assembly of the head of bacteriophage T4. Nature $227: 680-685$.

Li, H., Qiu, T., Gao, D. and Cao, Y. 2010. Medium optimization for production of gamma-amonobutyric acid by Lactobacillus brevis NCL912. Amino Acids. 38 : 1439-1445.

Lin, S.D., Mau, J.L., and Hsu, C.A. 2012. Bioactive components and antioxidants of tea leaves. Food Sci and Technol. $46:$ 64-70.

Lowery, O.H., Rosebrough, N.J., Farr, A.C., and Randall, R.J. 1951. Protein measurement with the Folin-phenol reagent. J. Biol. Chem. 193 : 265-275.

Maras, B., Sweeney, G., Barra, D., Bossa, F. and John, R.A. 1992. The amino acid sequence of glutamate decarboxylase from Escherichia coli. Eur J Biochem. 204 : 93-98.

Nomura, M., Kimoto, H., Someya, Y., Furukawa, S. and Suzuki, I. 1998. Production of ã-Aminobutyric acid by cheese starters during cheese ripening. Dairy Foods. 81 : 1486-1491.

Nomura, M., Nakajima, I., Fujita, Y., Kobayashi, M., Kimoto, H., Suzuki, I. and Aso, H. 1999. Lactococcus lactis contains only one glutamate decarboxylase gene. Microbiology. $145:$ 1375-1380.

Nomura, M., Kobayashi, M., Ohmomo, S. and Okamoto, T. 2000. Activation of the glutamate decarboxylase gene in Lactococcus lactis subsp. Cremoris. Appl Environ Microbiol. 66 : 2235-2237.

Noriko, K., Jun, S., Shinichi, K., Hiroh, M. and Toshinori, K. 2005. Production of ã-Aminobutyric acid (GABA) by Lactobacillus paracasei isolated from traditional fermented foods. Food microbiology. 22 : 497-504.

Saikusa, T., Horino, T. and Mori, Y. 1994. Accumulation of ãAminobutyric acid (Gaba) in the rice germ during water soaking. Biosci Biotech Biochem. 58 : 2291-2292.

Saitou, N. and Nei, M. 1987. The neighbor-joining method: a new method for reconstructing phylogenetic trees. Mol. Biol. Evol. 4 : 406-425.

Seher, Y., Filiz, O. and Melike, B. 2013. Gamma-amino butyric acid, glutamate dehydrogenase and glutamate decarboxylase levels in phylogenetically divergent plants. Plant Syst Evol. 299 : 403-412.

Smith, D.K., Kassam, T., Singh, B. and Elliott, J.F. 1992. Escherichia coli has two homologous glutamate decarboxylase genes that map to distinct loci. J Bacteriol. 174 : 5820-5826.

Stanton, H.C. 1963. Mode of action of gamma aminobutyric acid on the cardiovascular system. Arch Int Pharmacodyn. 143 : 195-200.

Kumar, S., K., Tamura, I. Jakobsen, B., and Nei, M. 2001. MEGA2: molecular evolutionary genetics analysis software. Bioinformatics. 17 : 1244-1245.

Tsushida, T. and Murai, T. 1987. Conversion of glutamic acid to $\gamma$-Aminobutyric acid in tea leaves under anaerobic conditions. Agric Biol Chem. 51 : 2865-2871.

Ueno, Y., Hayakawa, K., Takahashi, S. and Oda, K. 1997. Purification and characterization of glutamate decarboxylase from lactobacillus brevis IFO 12005. Biosci Biotec Biochem. 61 : 1168-1171.

Yu, J.J. and Oh, S.H. 2011. ã-Aminobutyric acid production and glutamate decarboxylase activity of Lactobacillus sakei OPK259 isolated from Kimchi. Korean J. Microbiol. 7 : 104-109. 